\title{
Exploring Social Problems in Tobago
}

\author{
Sharon Campbell-Phillips \\ Department of Education, University of the People, Pasadena, CA, USA \\ beautifulblushes@yahoo.com
}

\begin{abstract}
In Trinidad and Tobago, crime is escalating among our youths. These youths are teenagers who should be in school acquiring an education. Teenage crime is a name given to the crimes that are committed by people who are under the age of eighteen (18). In Trinidad and Tobago, most of the violent crimes are committed by children under the age of eighteen, who are either in school or have dropped out. Crimes committed mostly by teenagers include theft, assaults on other teenagers, gang violence, and even murder. Some of these juveniles are before the court defending themselves against crimes that they have committed, while others are in prison serving their sentences. Many of our youths are giving into social problems and neglecting the importance of their deviant behaviours. Social problem is a global epidemic that is affecting persons from all background, culture, race, age and belief. There have been patterns of negative behaviours among students in Tobago and it is becoming uncontrollable. Therefore, the aim of this study is to acquire information that can be used to help curb those unacceptable behaviours. Questionnaires were the method used and they were administered throughout the island of Tobago to persons belonging to different age groups. Based on the information gather and the findings, recommendations were suggested as a way of building better communities and a better Tobago. The purpose of this study is to explore social problems within Tobago and to identify the ways in which the youths are affected and by extension, the communities.
\end{abstract}

Keywords

social problems, Tobago, students, crime; community

\section{Introduction}

Patterns of crime among students are escalating among school dropouts within society. The theoretical model of this study proposes that the social bond is strengthened or weakened thought socialization experiences in the family, school, peer groups, and the community and that this process impacts on the issue of dropout status. The lack of opportunities in school, prosocial activities, and interaction with prosocial others increases the vulnerability of the at-risk child for dropping out. Although dropouts exhibit more frequent and serious crime among students, patterns of deviant behaviour vary according to the reasons for leaving school and the extent of other social and personal problems. Dropping out of school has many consequences including engaging in criminal activities, and criminal conviction. Logistic regression showed academic achievement, academic aspirations, and leaming-focused school settings to be related to a decline in deviant outcomes independent of the effects of disadvantaged socioeconomic background, low 
intelligence, childhood conduct problems, and having deviant friends during adolescence. Associations between school conflict and later deviancy were mediated by deviant peer relationships in adolescence and other school characteristics. Many research reporting continuity of childhood conduct problems and the influence of adolescent affiliations with deviant peers on negative outcomes was supported. Several theoretical positions can be appealed to concerning the relationship between dropping out of school and criminal activities. The two criminological theories that have received the most attention in relation to criminal behaviour in children are strain theory and social control theory. Today, there are a large number of juveniles dropping out of school for various reasons. The problem presents a domino effect. Essentially, once a juvenile dropout of the middle and high school, the likelihood of the juvenile dropout becoming deviant is very high. When students choose to leave the educational institution, they put themselves at a serious disadvantage. Society in general places a high premium on education. Education and the acquisition thereof support the direct connection to the job markets. Thus, the purpose of this research is only to detect and analysed the reasons why juveniles drop out of school and explore juvenile dropout acquaintance with the criminal justice system, as a result of their deviant behaviour. Fisher (2010) maintains juveniles who drop out of school engage in gang violence, child prostitution, and crime. Some of the more prevalent areas include single parent homes, peer pressure, and childhood pregnancies. This research provides an insight, which could promote a change in the educational system as well as a reduction in the number of juveniles who through their deviance, become incarcerated.

\section{Review of Literatures}

According to strain theory, delinquent conduct is an adaptation to a feeling of dissatisfaction, displeasure, or goal blockage. In traditional strain theory, youth who experience academic and social failure in school have two possible courses of action. One solution is to remain in school and reduce the strain produced by one's negative school experiences by engaging in delinquent conduct. Because delinquency provides a sense of status and success is not obtained in school, involvement in delinquency is predicted by the theory to lead to a reduction in strain, Cloward and Ohlin (1960); Cohen (1955). The second possible solution is to remove oneself from the source of strain and leave school, Elliott (1966) (1978); Elliott and Voss (1974). Once one has left school and no longer feels strained by school failure, the motivation for delinquent conduct is diminished. Therefore, traditional strain theorists would predict an inverse relationship between dropping out of school and subsequent delinquency because leaving school would reduce strain and, therefore, the primary motivation for delinquent conduct. This theory focuses on the relationship between demographic factors, such as socioeconomic status, gender and ethnicity, and dropout. Boys are much more likely to drop out than girls and dropouts are most likely from a family with a low socioeconomic status. There has been contention over the influence of ethnicity on dropout rates. However, it is clear that it does have some influence. Low socioeconomic status is a significant predictor of dropout beyond poor academic achievement.

In recent years and even in today's society, Trinidad and Tobago have been experiencing an increase of social problems within the educational system relating to school dropout and crime.

Many persons believe that the educational system is partly responsible for the number of school dropouts and criminal activities that exist among our youths, and therefore, needs to implement and/or modify its activities so that they can be served as crime prevention 
measures, and as a result, eliminate the amount of potential criminals that are within the schools. Most of these students, who have decided to give up on school and their education, began displaying their criminal behaviours within the school even before they became dropouts. It is clearly observed within our communities that a lot of our school dropouts are engaging in criminal activities. Even though school completion rates have continually grown during most of the past years, dropping out of school persists as a problem that interferes with educational system efficiency, and the most straightforward and satisfying route to individual educational goals for young people. There are many reasons why students drop out of school; some of these reasons are academic struggles, peer pressure, lack of parental support, lack of financial support etc. The cause of a student dropping out is often termed as the antecedent of dropout because it refers to the pivotal event which leads to dropout. This event, however, is the culmination of a much longer process of leaving school that began long before the date that a student actually discontinues attendance.

Dropping out of school is a serious national, state, and local problem. Students who drop out of school have fewer options for employment and are at greater risk of low selfesteem.

School dropouts usually end up working low-skilled and low-paying job-positions with fewer possibilities for advancement, or even engaging in criminal activities as a mean of survival or to fit within a gang/group. Crime is a negative externality with enormous social costs. If education reduces crime, then schooling will have social benefits that are not taken into account by individuals. The social return to education may exceed the private return. Given the large social costs of crime, even small reductions in crime associated with education may be economically important. There are a number of reasons to believe that education will affect subsequent crime. First, schooling increases the returns to legitimate work, raising the opportunity costs of illicit behaviour. Additionally, punishment for crime typically entails incarceration. By raising wage rates, schooling makes this 'lost time' costlier. Second, education may directly affect the financial or psychic rewards from crime itself. Finally, schooling may alter preferences in indirect ways, which may affect decisions to engage in crime. For example, education may increase one's patience or risk aversion. On net, we expect that most of these channels will lead to a negative relationship between education and typical violent and property crimes. Despite the many reasons to expect a causal link between education and crime, empirical research is not conclusive.

\section{Research Methods}

The current research seeks to answer the question: Does dropout from school have a causal impact on delinquent or criminal behaviour? The aim of this study is to understand how social problems are affecting individuals, schools, families and communities. Previous studies have neither been able to confirm or deny the causal nature of this relationship due to methodological challenges. The most intractable of these problems is their vulnerability to the charge of omitted variable bias, or more specifically, bias due to the effects of persistent pre-existing differences in the sample. Thus, many researchers seek solutions to the said problems. For the purpose of this research, questionnaires were used to gather information to bring answers to many unanswered questions. They were given to randomly selected persons who and they were asked to give their honest answers. They were informed that the questionnaires were anonymous and that it was confidential. They were also told that it is voluntary and their contributions were greatly appreciated, however, it was not mandatory. 


\section{Discussion}

Social problems are plaguing our society. It is undesirable and it disrupts and damages the growth of communities. Because of the severe effects of these problems, we interacted with residents of the community of Speyside, to get a clear understanding of the impact of the problems that are plaguing the community. We randomly interviewed persons, and they were very cooperative polite and happy to share their views, hoping that together we can create a solution to these problems. They are frustrated and fed-up with the stagnation of the community as a result of the problems faced. Fifty persons were interviewed on questions about social problems ranging from less destructive to most destructive. Twenty persons, twelve males and eight females, said that crime was the most dominant, fifteen persons, all females said that domestic violence was the most raging problem, ten persons, eight females and two males believed that teenage pregnancy was most striking among our youths, and five persons agreed that unemployment was the problem affecting the community most. The residents believe that social problems are not and should not be welcomed in any society, and even though they cause a direct disruption to individuals, they still exist, hence the reason our communities are suffering as a result of these problems being unsolved. This experiment was indeed a great experience. It was a great opportunity to interact with persons of different ages and background on a topic that is being discussed by most persons within the community as well as environs. Many of the older ones said that our country need constant prayers, and that the government needs to be more active and implement programs and activity groups to assist and educate persons, so that they can understand the severity of these problems. While interacting with these persons, many of them shared their experiences and how they are being affected.

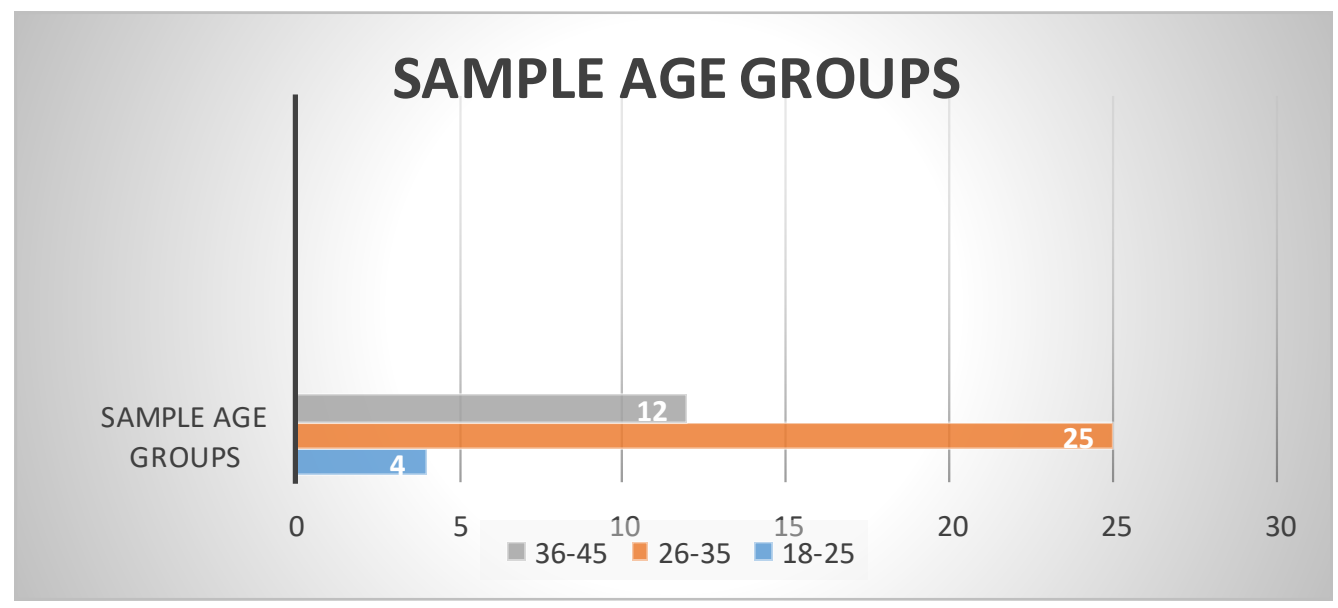

Figure 1 above illustrates the data collected on the range of ages to which members of the sample belonged. Of the 41, 12, being $29.27 \%$, fell in the $36-45$ age brackets. Of the 41 , 25 , being the greatest, were $61 \%$, fell in the $26-35$ age brackets. Finally, on 4 , being only $9.76 \%$ of the total sample, fell between the ages of 18-25. 


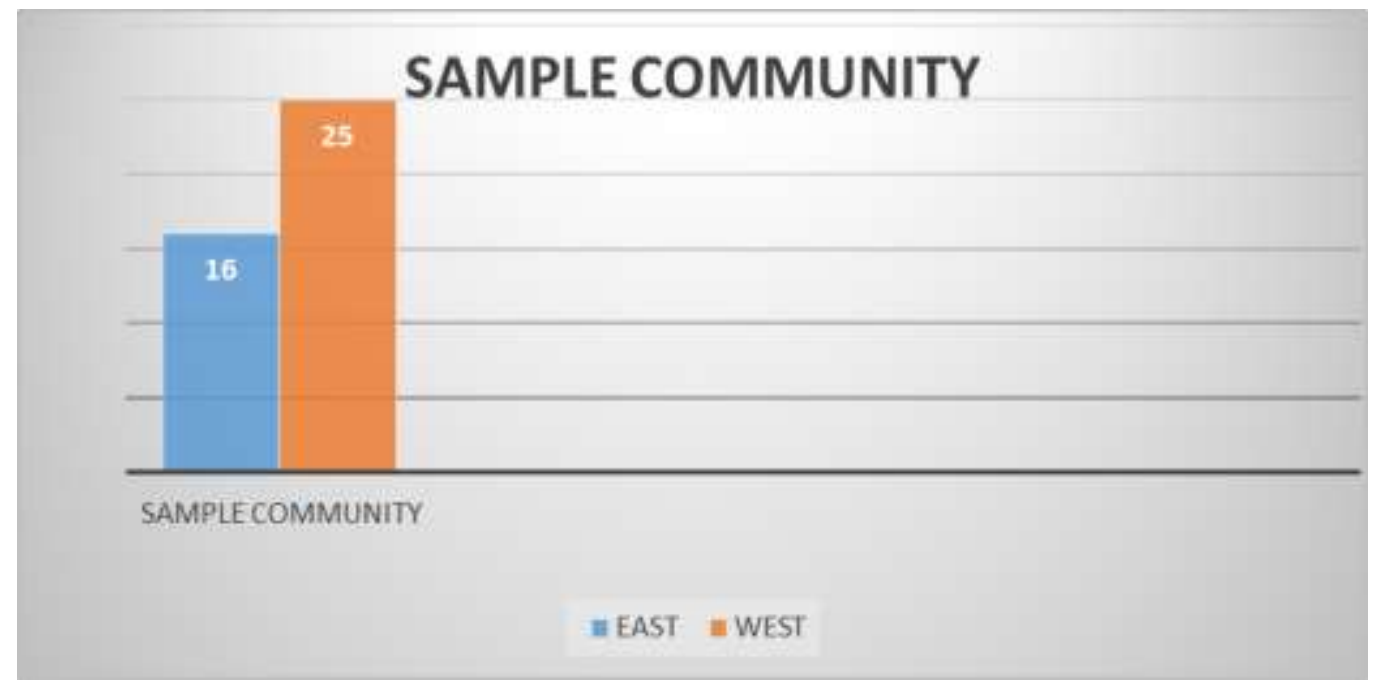

Figure 2 above illustrates the data collected on the different communities in which members of the sample belonged. Of the total sample, 39\% lived in the east and $61 \%$ came from the west.

\section{Conclusion}

Social problems are conditions or issues that negatively affects a person's state of being in a society, that people in a community view as being undesirable and such have been plaguing Trinidad and Tobago and everyone have been affected one way or another. There are many types of social problems that exists within communities which will be identified by person within various communities. When a society is affected by a social problem/s, the norms, values, customs and tradition change, as the society is disturbed by external or internal forces of social change which becomes unacceptable. Social problems affect our society adversely and disturb our harmony, which create dissatisfaction, suffering and misery. These problems may be difficult to solve but not impossible. However, as long as people are not aware of the problems, even though they exist, there will be no social disharmony, but maladjustment comes to the front only when the majority becomes conscious of it.

\section{References}

Adolescent School Experiencesand Dropout, Adolescent Pregnancy, and Young Adult Deviant Behavior. (n.d.). Retrieved April 30, 2016, from http://jar.sagepub.com/content/13/1/49.abstract

Dillon, S. (2009). Study Finds High Rate of Imprisonment Among Dropouts. Retrieved April 30, 2016, from http://www.nytimes.com/2009/10/09/education/09dropout.html?_r=0

Dillon, S. (2009). Study Finds High Rate of Imprisonment Among Dropouts. Retrieved April 30, 2016, from http://www.nytimes.com/2009/10/09/education/09dropout.html?_r=0

PUBLICATIONS. (n.d.). Retrieved April 30, 2016, from https://www.ncjrs.gov/App/publications/abstract.aspx?ID=122322. 